\title{
Henoch-Schönlein Purpura-Associated Hemorrhagic Shock After Secondary Norovirus Infection
}

\author{
Sara K. McLaughlin ${ }^{1}$, Lindsey Lawrence ${ }^{2}$, Jeremy Adler ${ }^{2}$, Hiral Mehta ${ }^{3}$ \\ 1. Pediatrics, University of Michigan, Ann Arbor, USA 2. Pediatric Gastroenterology, University of Michigan, Ann Arbor, \\ USA 3. Pediatrics, Children's Hospital of Philadelphia, Philadelphia, USA
}

Corresponding author: Sara K. McLaughlin, sarakm@umich.edu

\begin{abstract}
Henoch-Schönlein purpura (HSP) is a small-vessel vasculitis, typically involving the skin, joints, kidneys, and gastrointestinal (GI) tract. Although GI bleeding with HSP can occur, massive GI hemorrhage is rare. It is well documented that HSP can be triggered by a preceding infection, often of the upper respiratory tract. Infections that occur after the development of HSP and trigger worsening of the disease or new complications have not been well reported. We present the case of a three-year-old previously healthy boy who developed HSP with typical signs and symptoms, including hematochezia that resolved after treatment with intravenous steroids. The patient then contracted norovirus and subsequently developed massive GI bleeding, leading to hemorrhagic shock and requiring admission to an intensive care unit. This case demonstrates that secondary infection, such as norovirus infection, can precipitate worsening of underlying HSP vasculitis and lead to acute clinical decompensation. Clinicians should be aware of the risk of acute clinical changes in patients with HSP.
\end{abstract}

Review began 10/20/2020 Review ended 11/10/2020 Published 11/23/2020

\section{() Copyright 2020}

McLaughlin et al. This is an open access article distributed under the terms of the Creative Commons Attribution License CC-BY 4.0., which permits unrestricted use, distribution, and reproduction in any medium, provided the original author and source are credited.
Categories: Family/General Practice, Pediatrics, Gastroenterology Keywords: hemorrhagic shock, norovirus, henoch schönlein purpura

\section{Introduction}

Henoch-Schönlein purpura (HSP) is the most common systemic vasculitis in children, with an incidence of 10 to 30 per 100,000 children annually [1,2]. The classic presentation includes the tetrad of palpable purpura, arthritis or arthralgias, abdominal pain, and renal involvement [3]. Gastrointestinal (GI) manifestations of HSP occur in the majority of cases, most commonly as abdominal pain or GI bleeding [4]. Massive GI bleeding and hemorrhagic shock are rare, described in select case reports [5-7]. We present a case of HSP in a previously healthy three-year-old boy who demonstrated initial clinical improvement until he contracted norovirus and subsequently developed hemorrhagic shock.

\section{Case Presentation}

A three-year-old unimmunized boy with no significant past medical history developed abdominal pain, nausea, and vomiting. Five days later, he developed arthralgias and a palpable purpuric lower extremity rash; he presented to his pediatrician and was diagnosed with HSP. He was admitted to a local children's hospital from days six to eight of illness for hydration and pain management. On day 11 of illness, he presented to a different pediatric Emergency Department (ED) with abdominal pain and facial and scrotal edema and was admitted for dehydration. While hospitalized, he experienced multiple episodes of hematochezia, prompting initiation of intravenous (IV) methylprednisolone, $15 \mathrm{mg} / \mathrm{kg}$ for two doses. Abdominal ultrasound demonstrated thickened small bowel loops (without intussusception), consistent with HSP (Figure 1).
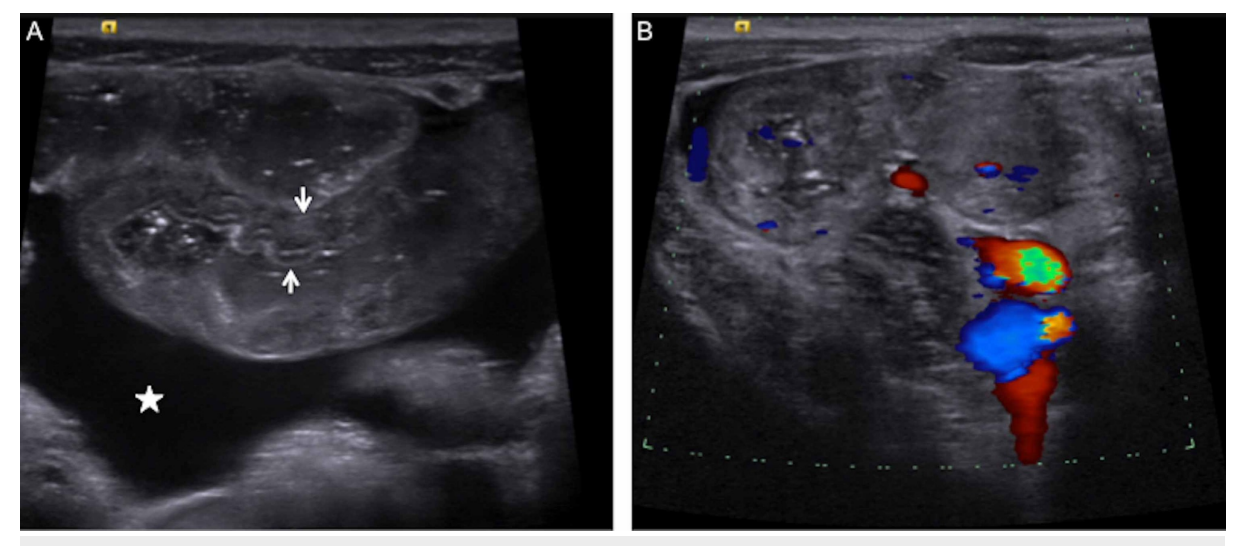


\section{Cureus}

\section{FIGURE 1: Abdominal Ultrasound}

A) Lower abdomen midline image demonstrating several loops of small bowel with concentric bowel thickening (between the arrows) and associated simple-appearing ascites (star). B) Right lower quadrant image with color Doppler demonstrating preserved bowel wall flow. Real-time scanning demonstrated no evidence of bowel intussusception or intraperitoneal fluid collection.

Hematochezia, edema, abdominal pain, and joint pain resolved after initiation of steroids, though the rash persisted. He was discharged on a month-long prednisone taper. Discharge laboratory studies were notable for leukocytosis, anemia, thrombocytosis, age-appropriate creatinine, hypoalbuminemia, and an elevated urine protein-to-creatinine ratio (UPC) (Table 1).

\begin{tabular}{|c|c|c|}
\hline Lab & Value & Reference Range \\
\hline White blood cell count & 18.7 K/uL & 6-15 K/uL \\
\hline Hemoglobin & 9.9 g/dL & 11-14 g/dL \\
\hline Hematocrit & $29.8 \%$ & $34-41 \%$ \\
\hline Platelet count & 482 K/uL & $150-400 \mathrm{~K} / \mathrm{uL}$ \\
\hline Sodium & $136 \mathrm{mmol} / \mathrm{L}$ & 132-145 mmol/L \\
\hline Potassium & 4.0 mmol/L & $3.3-5.0 \mathrm{mmol} / \mathrm{L}$ \\
\hline Chloride & 103 mmol/L & 98-108 mmol/L \\
\hline Bicarbonate & 25 mmol/L & $18-28$ mmol/L \\
\hline Blood Urea Nitrogen & 7 mg/dL & $5-20$ mg/dL \\
\hline Creatinine & $0.21 \mathrm{mg} / \mathrm{dL}$ & $0.20-0.60$ mg/dL \\
\hline Glucose & 96 mg/dL & $50-130 \mathrm{mg} / \mathrm{dL}$ \\
\hline Albumin & 3.0 g/dL & $3.2-5.2$ g/dL \\
\hline Urine protein-to-creatinine ratio & 0.23 & $0.01-0.18$ \\
\hline
\end{tabular}

TABLE 1: Initial Admission Discharge Laboratory Studies

Three days later, on day 17 of illness, the patient acutely developed abdominal pain, non-bloody emesis, and hematochezia, which progressed to a large volume of bright red blood per rectum, prompting representation to the ED. On arrival, the patient was ashen and unresponsive. Vital signs were notable for heart rate 150 beats per minute and blood pressure $80 / 50 \mathrm{mmHg}$. Mucous membranes were dry. Extremities were cool with weak pulses and capillary refill greater than five seconds, consistent with class III-IV hemorrhage and hypovolemic shock. Petechiae and purpura were noted on bilateral lower extremities. Laboratory studies showed marked leukocytosis, thrombocytosis, and uremia reflecting hemoconcentration (Table 2). 


\section{Cureus}

\begin{tabular}{|lll|}
\hline Lab & Value & Reference Range \\
\hline White blood cell count & $63.6 \mathrm{~K} / \mathrm{uL}$ & $6-15 \mathrm{~K} / \mathrm{uL}$ \\
Hemoglobin & $12.2 \mathrm{~g} / \mathrm{dL}$ & $11-14 \mathrm{~g} / \mathrm{dL}$ \\
Hematocrit & $37.2 \%$ & $34-41 \%$ \\
Platelet count & $1,176 \mathrm{~K} / \mathrm{uL}$ & $150-400 \mathrm{~K} / \mathrm{uL}$ \\
Sodium & $142 \mathrm{mmol} / \mathrm{L}$ & $132-145 \mathrm{mmol} / \mathrm{L}$ \\
Potassium & $4.6 \mathrm{mmol} / \mathrm{L}$ & $3.3-5.0 \mathrm{mmol} / \mathrm{L}$ \\
Chloride & $104 \mathrm{mmol} / \mathrm{L}$ & $98-108 \mathrm{mmol} / \mathrm{L}$ \\
Bicarbonate & $24 \mathrm{mmol} / \mathrm{L}$ & $18-28 \mathrm{mmol} / \mathrm{L}$ \\
\hline Blood Urea Nitrogen & $24 \mathrm{mg} / \mathrm{dL}$ & $5-20 \mathrm{mg} / \mathrm{dL}$ \\
Creatinine & $0.42 \mathrm{mg} / \mathrm{dL}$ & $0.20-0.60 \mathrm{mg} / \mathrm{dL}$ \\
\hline Glucose & $198 \mathrm{mg} / \mathrm{dL}$ & $50-130 \mathrm{mg} / \mathrm{dL}$ \\
Albumin & $3.7 \mathrm{~g} / \mathrm{dL}$ & $3.2-5.2 \mathrm{~g} / \mathrm{dL}$ \\
\hline Urine protein-to-creatinine ratio & 0.42 & $0.01-0.18$ \\
\hline
\end{tabular}

\section{TABLE 2: Re-Presentation Initial Laboratory Studies}

He was fluid resuscitated with $60 \mathrm{ml} / \mathrm{kg}$ normal saline and $10 \mathrm{ml} / \mathrm{kg}$ red blood cells. Following resuscitation, laboratory studies were notable for leukocytosis, worsened anemia, thrombocytosis, and worsened hypoalbuminemia (Table 3).

\begin{tabular}{|c|c|c|}
\hline Lab & Value & Reference Range \\
\hline White blood cell count & $16.3 \mathrm{~K} / \mathrm{uL}$ & 6-15 K/uL \\
\hline Hemoglobin & 8.4 g/dL & $11-14 \mathrm{~g} / \mathrm{dL}$ \\
\hline Hematocrit & $25.5 \%$ & $34-41 \%$ \\
\hline Platelet count & $442 \mathrm{~K} / \mathrm{uL}$ & $150-400 \mathrm{~K} / \mathrm{uL}$ \\
\hline Sodium & $140 \mathrm{mmol} / \mathrm{L}$ & 132-145 mmol/L \\
\hline Potassium & $4.4 \mathrm{mmol} / \mathrm{L}$ & 3.3-5.0 mmol/L \\
\hline Chloride & $110 \mathrm{mmol} / \mathrm{L}$ & 98-108 mmol/L \\
\hline Bicarbonate & $25 \mathrm{mmol} / \mathrm{L}$ & $18-28 \mathrm{mmol} / \mathrm{L}$ \\
\hline Blood Urea Nitrogen & 10 mg/dL & $5-20 \mathrm{mg} / \mathrm{dL}$ \\
\hline Creatinine & $0.21 \mathrm{mg} / \mathrm{dL}$ & $0.20-0.60 \mathrm{mg} / \mathrm{dL}$ \\
\hline Glucose & $145 \mathrm{mg} / \mathrm{dL}$ & $50-130$ mg/dL \\
\hline Albumin & $2.7 \mathrm{~g} / \mathrm{dL}$ & $3.2-5.2 \mathrm{~g} / \mathrm{dL}$ \\
\hline
\end{tabular}

\section{TABLE 3: Post-Resuscitation Laboratory Studies}

Abdominal ultrasound revealed dilated loops of edematous bowel, similar to the prior ultrasound, still without signs of intussusception (Figure 2). 


\section{Cureus}

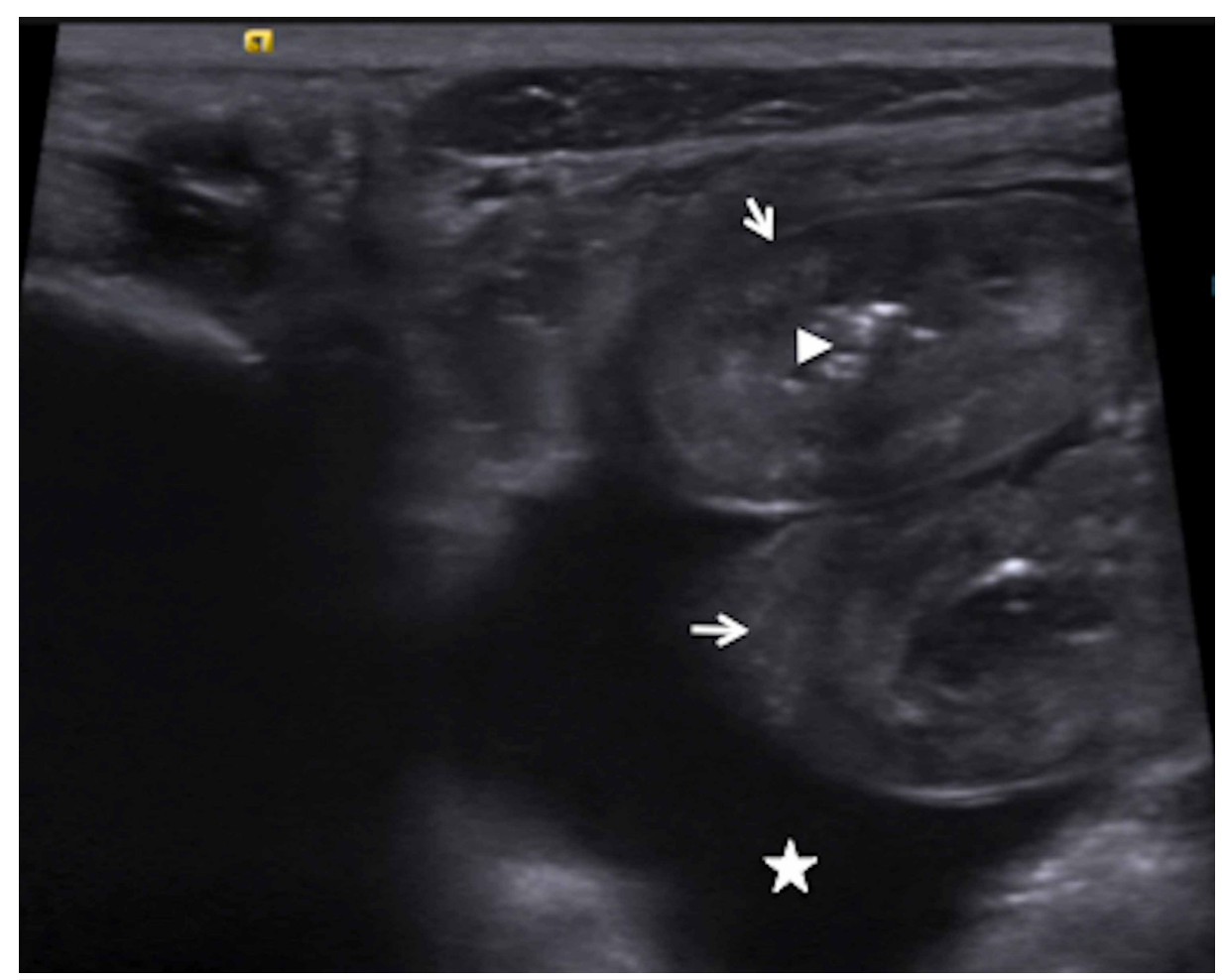

\section{FIGURE 2: Repeat Abdominal Ultrasound}

Image of the lower abdomen midline. Again several loops of small bowel with concentric bowel thickening (arrows) and associated simple-appearing ascites (star) are seen. Some bowel loops are fluid-filled, debrisfilled and/or gas-filled (arrowhead demonstrates gas in the lumen). Real-time scanning showed no bowel intussusception or intraperitoneal fluid collection.

The patient was started on IV methylprednisolone and a pantoprazole infusion. Endoscopy was not performed as risks of perforation with hypoalbuminemia and vasculitis outweighed potential benefit. Hypotension resolved and the patient's mental status began improving although he remained lethargic. He was admitted to the pediatric intensive care unit (PICU) for further management of hemorrhagic shock and for close monitoring given continued concerning clinical status.

Given the patient's unvaccinated status, ill appearance, and leukocytosis raising concern for sepsis, blood and urine cultures were collected and he was started on piperacillin-tazobactam. Cultures came back negative and the antibiotic was discontinued. Gastrointestinal antigen panel, obtained to evaluate for infectious etiologies, was positive for norovirus; additional history-taking revealed that the patient's siblings had developed typical symptoms of viral gastroenteritis the preceding day. Antineutrophil cytoplasmic antibodies and antistreptolysin $\mathrm{O}$ titers were negative. Once started on methylprednisolone and pantoprazole, GI bleeding resolved within 24 hours and hemoglobin stabilized. The patient's mental status returned to baseline, suggesting initial alteration was due to shock rather than central nervous system HSP involvement. He was transitioned to an oral steroid taper, transferred to a general pediatrics unit, and discharged home eight days following admission. He remained free of GI bleeding and overall symptom-free at follow-up visits, with a normalized UPC.

\section{Discussion}

HSP is the most common vasculitis in children $[8,9]$. In addition to the classic tetrad of palpable purpura or petechiae, arthritis or arthralgias, abdominal pain, and renal involvement, HSP also can affect the central nervous system, scrotum, lungs, and GI tract [8]. GI manifestations occur in the majority of patients, most commonly as post-prandial epigastric or periumbilical abdominal pain, similar to bowel angina/ischemia. In fact, earlier HSP literature referred to "bowel angina" as a diagnostic criterion [10]. Intussusception is the most common surgical complication of HSP, with an incidence of 1-14\%, presumably due to a lead point from intramural hemorrhage or edema. Other GI complications include perforation, obstruction, stricture, and GI bleeding [11].

GI bleeding occurs in 18-52\% of cases of HSP [11] and typically is mild, presenting as melena or hematochezia $[4,11]$. Although uncommon, cases of severe GI hemorrhage with HSP have been reported. Massive GI bleeding in these cases was attributed to the natural history of HSP [5,7], illness-related stress gastritis [6], or possibly a complication of treatment of the initial disease [12]. No secondary insults 
(infection, injury, etc.) were reported, although in one case, hemorrhage did not occur until three weeks after HSP diagnosis [6]. Severe GI involvement is more common in adults with HSP, with one study reporting a prevalence of $48 \%$. Half of those with GI involvement had serious GI bleeding, and of those, $11 \%$ required transfusion, or surgery, or their bleeding led to death [13].

In this case, the patient acutely developed GI bleeding and hemorrhagic shock on day 17 of illness, despite resolution of mild hematochezia for the preceding four days. These developed after the patient contracted norovirus. Since the introduction of the rotavirus vaccine, norovirus has emerged as the leading cause of medically-attended gastroenteritis in children in the United States [14]. Norovirus commonly presents with vomiting, non-bloody diarrhea, and abdominal pain, but very rarely is associated with GI bleeding [15]. GI pathogens including shigella, salmonella, campylobacter, and, less commonly, norovirus, have been reported to precede the development of HSP [11,16]. To our knowledge, there have not been reports of norovirus infection following a primary HSP diagnosis and triggering a complication or clinical worsening. Additionally, none of the previously-reported cases of GI hemorrhage in HSP described a secondary infection thought to precipitate or exacerbate the bleed.

Our patient's GI bleed cannot readily be attributed to a more common or previously-described etiology: Although endoscopy was not performed, we do not believe the patient had an underlying gastritis or ulcer. Their natural history is not consistent with the acute onset of bright red blood per rectum that resolves promptly with steroids. Intussusception, a GI complication of HSP, typically presents with pain but can include rectal bleeding; our patient had serial imaging negative for intussusception. Our patient did not have thrombocytopenia or a coagulopathy. Other causes of GI bleeding include vascular malformation, polyp, or Meckel's diverticulum; none would be expected to resolve with steroid administration. Our patient's ultrasound imaging did show thick-walled small bowel, as seen in HSP small bowel vasculitis, and bleeding improved with steroids, all consistent with bleeding secondary to HSP vasculitis.

Interestingly, norovirus has been described with hematochezia in patients with inflammatory bowel disease (IBD) who contract the infection [17]. In the general population, norovirus infection alone typically does not cause GI bleeding. In the case of IBD, norovirus is thought to precipitate a disease flare resulting in bleeding, and does not directly cause GI bleeding. Research into mechanisms of norovirus pathology in general is limited due to an inability to culture the virus and a lack of animal models [18]. In our case, the patient developed hemorrhagic shock after contracting norovirus infection while recovering from HSP. It is possible that norovirus caused massive GI bleeding via an increase in the inflammation of perivasculitis. It also is possible that norovirus led to worsening of HSP through another mechanism. Since resolution of HSP and norovirus infection, our patient has been well and has no evidence of IBD. As there was no evidence of alternative causes of GI bleed, we hypothesize that introduction of norovirus to a GI tract inflamed from HSP led to severe bleeding in our patient's case.

\section{Conclusions}

We describe the case of a three-year-old previously healthy boy who developed HSP. After clinical improvement and resolution of initial hematochezia, the patient contracted norovirus and developed massive GI bleeding, leading to hemorrhagic shock requiring transfusion and PICU admission. To our knowledge, GI viral infection in the setting of preceding HSP and leading to massive GI bleed has not been reported previously. Clinicians should be aware of the risk of severe late GI bleeds in patients with HSP and provide anticipatory guidance to families as well, as these complications can be acutely life-threatening and require immediate medical attention, as in our patient's case.

\section{Additional Information \\ Disclosures}

Human subjects: Consent was obtained by all participants in this study. Conflicts of interest: In compliance with the ICMJE uniform disclosure form, all authors declare the following: Payment/services info: All authors have declared that no financial support was received from any organization for the submitted work. Financial relationships: All authors have declared that they have no financial relationships at present or within the previous three years with any organizations that might have an interest in the submitted work. Other relationships: All authors have declared that there are no other relationships or activities that could appear to have influenced the submitted work.

\section{Acknowledgements}

The authors would like to thank Dr. Maria Ladino-Torres for assistance in selecting representative ultrasound images.

\section{References}

1. Dolezalová P, Telekesová P, Nemcová D, Hoza J: Incidence of vasculitis in children in the Czech Republic: 2year prospective epidemiology survey. J Rheumatol. 2004, 31:2295-2299.

2. Penny K, Fleming M, Kazmierczak D, Thomas A: An epidemiological study of Henoch-Schönlein purpura . 
Paediatr Nurs. 2010, 22:30-35. 10.7748/paed2010.12.22.10.30.c8135

3. Rook A: William Heberden's cases of anaphylactoid purpura. Arch Dis Child. 1958, 33:271.

10.1136/adc.33.169.271

4. Chang WL, Yang YH, Lin YT, Chiang BL: Gastrointestinal manifestations in Henoch-Schönlein purpura: a review of 261 patients. Acta Paediatr. 2004, 93:1427-1431. 10.1080/08035250410020181

5. Fagbemi AA, Torrente F, Hilson AJ, Thomson MA, Heuschkel RB, Murch SH: Massive gastrointestinal haemorrhage in isolated intestinal Henoch-Schonlein purpura with response to intravenous immunoglobulin infusion. Eur J Pediatr. 2007, 166:915-919. 10.1007/s00431-006-0337-3

6. Weber TR, Grosfeld JL, Bergstein J, Fitzgerald J: Massive gastric hemorrhage: an unusual complication of Henoch-Schönlein purpura. J Pediatr Surg. 1983, 18:576-578. 10.1016/s0022-3468(83)80362-5

7. Goldbloom RB, Drummond KN: Anaphylactoid purpura with massive gastrointestinal hemorrhage and glomerulonephritis. An unusual case treated successfully with azathioprine and corticosteroids. Am J Dis Child. 1968, 116:97-102. 10.1001/archpedi.1968.02100020099015

8. Reid-Adam J: Henoch-Schonlein purpura. Pediatr Rev. 2014, 35:447-449. 10.1542/pir.35-10-447

9. Trnka P: Henoch-Schönlein purpura in children. J Paediatr Child Health. 2013, 49:995-1003. 10.1111/jpc.12403

10. Mills JA, Michel BA, Bloch DA, et al.: The American College of Rheumatology 1990 criteria for the classification of Henoch-Schönlein purpura. Arthritis Rheum. 1990, 33:1114-1121. 10.1002/art.1780330809

11. Ebert EC: Gastrointestinal manifestations of Henoch-Schonlein purpura. Dig Dis Sci. 2008, 53:2011-2019. 10.1007/s10620-007-0147-0

12. Clark JH, Fitzgerald JF: Hemorrhagic complications of Henoch-Schönlein syndrome. J Pediatr Gastroenterol Nutr. 1985, 4:311-315. 10.1097/00005176-198504000-00028

13. Pillebout E, Thervet E, Hill G, Alberti C, Vanhille P, Nochy D: Henoch-Schönlein purpura in adults: outcome and prognostic factors. J Am Soc Nephrol. 2002, 13:1271-1278. 10.1097/01.asn.0000013883.99976.22

14. Payne DC, Vinjé J, Szilagyi PG, et al.: Norovirus and medically attended gastroenteritis in U.S. children . N Engl J Med. 2013, 368:1121-1130. 10.1056/NEJMsa1206589

15. Robilotti E, Deresinski S, Pinsky BA: Norovirus. Clin Microbiol Rev. 2015, 28:134-164. 10.1128/CMR.0007514

16. Hwang HH, Lim IS, Choi BS, Yi DY: Analysis of seasonal tendencies in pediatric Henoch-Schönlein purpura and comparison with outbreak of infectious diseases. Medicine. 2018, 97:e12217. 10.1097/MD.0000000000012217

17. Khan RR, Lawson AD, Minnich LL, et al.: Gastrointestinal norovirus infection associated with exacerbation of inflammatory bowel disease. J Pediatr Gastroenterol Nutr. 2009, 48:328-333. 10.1097/mpg.0b013e31818255cc

18. Karst SM, Wobus CE, Lay M, Davidson J, Virgin HW: STAT1-dependent innate immunity to a Norwalk-like virus. Science. 2003, 299:1575-1578. 10.1126/science.1077905 